\title{
Effect of foaming agent concentration and drying temperature on biochemical properties of foam mat dried tomato powder
}

\author{
Hossain, M.A., Mitra, S., Belal, M. and *Zzaman, W. \\ Department of Food Engineering and Tea Technology, Shahjalal University of Science and Technology, \\ Sylhet-3114, Bangladesh
}

\author{
Article history: \\ Received: 21 July 2020 \\ Received in revised form: 3 \\ September 2020 \\ Accepted: 31 October 2020 \\ Available Online: 17 January \\ 2021 \\ Keywords: \\ Carboxymethyl Cellulose \\ (CMC), \\ Egg white, \\ Foam mat drying, \\ Tomato, \\ $\beta$-Carotene
}

DOI:

https://doi.org/10.26656/fr.2017.5(1).372

\begin{abstract}
The purpose of the study was to optimize the effective drying conditions and different foaming agent concentrations on the biochemical properties of foam mat dried tomato powder. Foaming was achieved by using egg albumin as foaming agent and sodium salt of Carboxymethyl Cellulose (CMC) as foam stabilizer with different concentrations. Drying was achieved by using different drying temperatures. The changes in different physicochemical properties of foam mat dried powder viz. total soluble solid (TSS), pH, ascorbic acid, titratable acidity, $\beta$-Carotene, DPPH radical scavenging activity were observed. Foams were prepared from different concentrations of egg albumin $(3-7 \% \mathrm{w} / \mathrm{w})$ and sodium salt of Carboxymethyl Cellulose $(1 \%, 0.5 \%)$. The drying temperatures were varied from $60^{\circ} \mathrm{C}$ to $70^{\circ} \mathrm{C}$. The drying time changes with different drying temperatures. It was found that the drying time decreased with the increased foaming agent concentrations as well as with higher drying temperature. It takes almost $13 \mathrm{hrs}$ for drying at $70^{\circ} \mathrm{C}$. TSS and $\mathrm{pH}$ content was increased with the increase of foaming agent concentrations and foam stabilizer's concentrations but decreased with the increasing temperatures. Ascorbic acid decreased with the increase of foaming agent concentrations and temperatures but increased with CMC concentration. Titratable acidity content of foam mat dried tomato powder was decreased with the increasing foaming agent concentrations but increased with the higher temperatures and decreased CMC concentration. $\beta$-Carotene contents increased with the increase of foaming agent concentrations but decreased with the increase of temperatures and foam stabilizer concentration. DPPH free radical scavenging activity increased with the increase of foaming agent, foam stabilizer and temperatures. Based on the maximum retention of physicochemical properties, the optimum treatment of foaming agent was found to be $7 \%$ egg white $+1 \% \mathrm{CMC}$ at $60^{\circ} \mathrm{C}$.
\end{abstract}

\section{Introduction}

Tomato (Solanum lycopersicum M.) is an important vegetable crop owing to its economical and nutritive significance belonging to the Solanaceae family. Tomato is taken not only the fresh state but also process it into different types of food such as juice, puree, sauce, and canned (Kadam and Balasubramanian, 2011). Tomato is a great source of essential nutrients, which increases its acceptance besides its aesthetic appeal (Abushita et al., 1997). With the increasing demand, tomato production in Bangladesh increases every year. In 20152016 ,Bangladesh produces almost 3,68,121 metric tons tomato and in 2016-2017, it increases to 3, 88,725 (BBS, 2017).
Moisture content in tomato is almost 93-95\% which increases its perishability and makes a great difficulty in its storage and transportation (Shan et al., 2016). To overcome post-harvest losses of tomato, it is processed into different types of products to increase their shelf life and availability all the year round (Clinton, 1998; Kadam and Balasubramanian, 2011; Affandi et al., 2017). The most common method of preservation is drying tomato in the form of powder, which can be reconstituted into juice and different tomato-based products like ketchup, sauce, chutney, soups etc. can be prepared (Kadam and Balasubramanian, 2011).

Drying is a process of simultaneous heat and mass transfer, which consists removal of water or another solvent from material by evaporation. Moisture in a food converts into vapor by radiation, convection, conduction 
heat transfer and those vapors are removed by employing forced air. Removal of moisture brings changes in the quality of the product as well as its nutritive value (Mujumder and Devahastin, 2006; Zhang et al., 2006; Varastegani et al., 2017). Generally, drying reduces water activity in food to a certain level which makes it difficult for micro-organisms to sustain and grow and increases its shelf life (Zzaman et al., 2014; Zzaman et $a l ., 2021)$. Drying also reduces the weight and volume of food by removing moisture, which reduces the cost of transportation and makes the material easy for handling (Doymaz, 2007; Kadam et al., 2009). Currently, for fruit powder production, different drying methods such as drum drying, freeze drying, spray drying and foam-mat drying are being used. The high temperature used in drum drying process causes loss of nutritional quality and creates unwanted odors in the final products (Nindo and Tang, 2007). Freeze drying and spray drying give good quality products having good rehydration ability and the color of the final products are also good. Due to high-cost production, these processes are used only for premium quality products (Ratti, 2001; Hsu et al., 2003).

Foam mat drying is a drying process where a liquid food product like fruit juices or semi-solid food products like vegetable puree, cereal pastes are whipped with an edible foaming agent with/without foam stabilizer to make stable foam. Then the stabilized foams are placed in a tray in a uniform layer followed by drying. The dried product is then scraped off and converted into fine powders by grinders and sealed immediately to stop moisture absorption (Ratti and Kudra, 2006; Rajkumer et al., 2006). Compared to other drying processes, it is less expensive, less complicated, less time consuming as well as retains better products quality than other drying techniques (Febrianto et al., 2012). Because of being the simplest forms of drying, foam-mat dried products gain consumers' attention in recent years. Foamed material takes lower drying time than non-foamed materials and in the final stages of drying. Many investigators found that the drying rate is enhanced because of the increased interfacial area of foamed materials (Wilson et al., 2012). Foam mat dried powder is rich in biochemical composition than non-foam dried powder. Powder from foam-mat drying is almost similar to the fresh sample in color, flavor and in taste (Kandasamy, 2012). This study was carried out to select the effective foaming agent and foam stabilizer concentrations for foam-mat dried tomato powder based on biochemical properties.

\subsection{Materials}

Fresh ripen tomato was purchased from Modina Market, Sylhet, Bangladesh and used as raw materials. Egg white was used as a foaming agent purchased from Modina Market, Sylhet. Sodium salt of carboxymethyl cellulose (CMC) CAS No.9004-32-4 (food grade) of Dalian Chem was used as a foam stabilizer. The whole study was conducted at the laboratory of Food Engineering and Tea Technology, Shahjalal University of Science and Technology, Sylhet-3114.

\subsection{Methodology}

Tomato was washed with running tap water to remove unwanted external material such as dust, clay etc. Then, they were cut with a stainless steel knife and passed through a Juice Extractor (Panasonic MJ M176P) to make tomato juice. The working flow sheet for the preparation of foam mat tomato powder is shown in Figure 1. Then the juice was pasteurized at $85^{\circ} \mathrm{C}$ temperatures for 3 mins. Before the formation of foam, the biochemical analysis of fresh tomato juice was performed in order to identify the relative quantity loss of total soluble solids (TSS), $\mathrm{pH}$, ascorbic acid, titratable acidity, beta carotene, DPPH in tomato juice powder in contrast with the fresh juice. Foaming was achieved by adding foaming agent and foam stabilizer in different concentrations at a whipper. Egg white was used as a foaming agent and sodium salt of carboxymethyl cellulose in different concentrations. An amount of 300 $\mathrm{mL}$ tomato juice was taken for each sample along with the selected concentrations of egg albumin $(3 \%, 5 \%, 7 \%$ $\mathrm{v} / \mathrm{v})$ and sodium salt of carboxymethyl cellulose $(0.5 \%$, $1 \%)$. Then the mixers were whipped at the whipper for 5 mins at maximum speed.

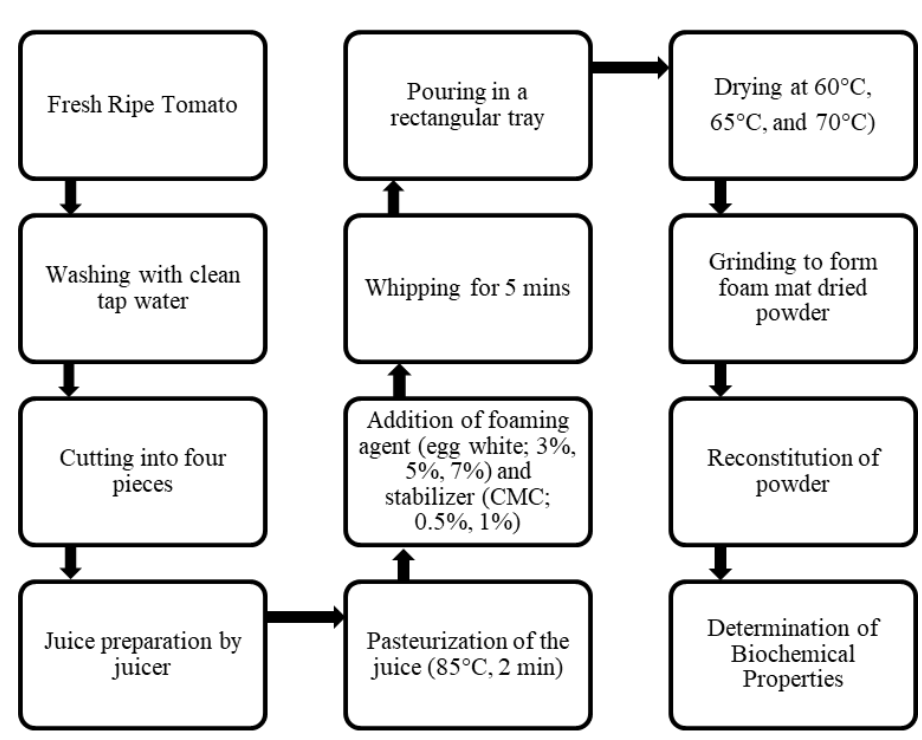

Figure 1. Working flow sheet for preparation of foam mat tomato powder 
The foamed tomato juice was then poured in a tray (stainless steel) and placed in an oven dryer at $60^{\circ} \mathrm{C}, 65^{\circ}$ $\mathrm{C}$, and $70^{\circ} \mathrm{C}$ for drying. After drying, the dried tomato juice was ground to form powder. Then the tomato powder was reconstituted. The reconstitution of powder was done by the method of Goula and Adamopoulos (2010) with few alternations. For reconstitution, $2 \mathrm{~g}$ of powder was mixed with $50 \mathrm{~mL}$ distilled water in a 100 $\mathrm{mL}$ glass beaker in room temperature and the mixture was agitated with the vortex at high speed. The reconstituted sample was used to determine the amount of TSS, pH, titratable acidity, ascorbic acid, beta carotene, DPPH radical scavenging assay.

\subsection{Determination of biochemical properties}

\subsubsection{Total soluble solids (TSS)}

Estimation of TSS was done with a Brix scale hand refractometer. For this, 1-2 drops of the reconstituted sample were placed between the prism and small covering plate of the refractometer. A shadow line forms between the brightened and the dark area in the refractometer shows the reading, where the shadow line crosses the scale.

\subsubsection{Ascorbic acid}

Ascorbic acid content in reconstituted foam mat dried tomato powder was determined following the method of Moazzem et al. (2019). About $5 \mathrm{~mL}$ sample was taken and made up to $50 \mathrm{~mL}$ with $3 \% \mathrm{HPO}_{3}$. After that filtration was done using Whatman No. 2 filter paper. Approximately, $10 \mathrm{~mL}$ of filtrate was taken with $10 \mathrm{~mL} \mathrm{HPO}_{3}$ titrate it with the 2,6 dichlorophenolindophenol until it turned into pink color endpoints and the color persists in the solution for almost $15 \mathrm{~s}$. Approximately, $5 \mathrm{~mL}$ standard ascorbic acid solution with $5 \mathrm{~mL} 3 \% \mathrm{HPO}_{3}$ was taken in a beaker and then filled the burette with dye solution and titrate the mixture solution with the dye solution until it turned into pink color which persists for almost $15 \mathrm{~s}$. Dye factor in $\mathrm{mg}$ of ascorbic acid per $\mathrm{mL}$ of the dye factor is calculated by using the following formula: Dye factor $=0.5 /$ titre .

Ascorbic acid per $100 \mathrm{~g}=\frac{\text { titre } \times \text { dye factor } \times \text { volume made up } \times 100}{\text { aliquiot extract taken for estimation } \times \text { weight of sample }}$

\subsection{3 $\mathrm{pH}$ determination}

The $p H$ of reconstituted foam mat tomato dried tomato was performed by a digital $\mathrm{pH}$ meter (HI- 2211, USA). The $\mathrm{pH}$ meter determines the amount of hydrogen -ion in a water-based solution, which shows its acidity or alkalinity figured as $\mathrm{pH}$ (Encyclopedia Britannica Online, 2016).

\subsubsection{Titratable acidity}

Titratable acidity of reconstituted foam mat dried tomato powder was determined as percentage of anhydrous citric acid. For this, the aliquot of the sample was diluted with water to make a fixed volume. Then it was titrated with $0.1 \mathrm{~N} \mathrm{NaOH}$ and as an indicator phenolphthalein was used. The percent acidity was calculated by using this formula:

Titre $\times$ Normality of alkali $\times$ Equivalent weight of acid $\times 100$ Total acid $(\%)=\frac{\text { Volume of sample taken for estimation } \times \text { weight or volume of sample taken } \times 100}{100}$

\subsubsection{Beta-carotene content}

The $\beta$-Carotene of reconstituted foam mat dried tomato powder was determined according to the method of Biswas and Chatli (2011). In a test tube, $1 \mathrm{~g}$ of reconstituted tomato juice was added with $5 \mathrm{~mL}$ chilled acetone. Then it was shaking occasionally for 15 mins. Then it was vortexed in a vortex (Model-VM2000, Taiwan) for 15 mins at high speed. Then it was centrifuged for 10 mins with a centrifuge (Model-416G, Gyrozen, Korea) at $1370 \mathrm{rpm}$. The supernatant was then separated in a test tube. Again, this process was run once more with the remaining compounds with the addition of $5 \mathrm{~mL}$ chilled acetone. The supernatant was then filtered with a Whatman No. 1 filter paper. Then, $0.025 \mathrm{~g}$ of standard $\beta$-Carotene was mixed with $5 \mathrm{~mL}$ acetone and kept in a dark place for 10 mins. The absorbance of extract and standard solution of $\beta$-Carotene was measured by using UV-Vis spectrophotometer at $449 \mathrm{~nm}$ wavelength (Model-1800, Shimadzu).

Weight of $\beta-$ carotene in sample $=\left(\frac{\text { Weight of } \beta \text {-Carotene }}{\text { Absorbance of standard } \beta \text {-Carotene }} \times\right.$ Absorbance of sample $) \times 1000 \mathrm{mg}$

\subsubsection{DPPH radical scavenging activity}

The DPPH radical scavenging activity of reconstituted sample was determined following the process of Kalantzakis et al. (2006). To make methanol extracts, $2.5 \mathrm{~g}$ tomato powder was dissolved in $10 \mathrm{~mL}$ of $70 \%$ methanol in a test tube. The mixture was then vortexed to mix well by a high-speed vortex meter. Then the mixture was centrifuged at $3500 \mathrm{rpm}$ with a centrifuge (Model-416G, Gyrozen, Korea) for 15 mins. After that, the mixture was filtered with Whatman No. 1 filter paper and then the filtrate was shifted into a glass bottle. The extracted sample was kept in the freezer for further analysis. After that, $1 \mathrm{~mL}$ of extracted sample was taken in a test tube with $4 \mathrm{~mL}$ DPPH solution and shaken. Then the sample was let stand for 30 mins at a dark place. Then after 30 mins the absorbance was read at $515 \mathrm{~nm}$ at a UV-Vis spectrophotometer. DPPH solution except extract was taken as control. Percentage of DPPH radical scavenging activity was calculated from the following equation: 
$\%$ scavenging of DPPH $=\left(1-\frac{\text { Absorbance of sample }}{\text { Absorbance of control }} \times 100\right)$

\section{Results and discussion}

\subsection{Total soluble solids}

Total soluble solids of different samples at different drying temperatures are presented in Table 1. For fresh tomato juice, TSS was found to be $4.5^{\circ}$ Brix and in reconstituted foam mat dried tomato powder it was varied from $3.84 \pm 0.04$ to $4.10 \pm 0.03^{\circ}$ Brix. It was found that TSS content in dried tomato powder raised with the increasing concentration of foaming agent as well as foam stabilizer concentrations because of some inherent component in egg white. TSS content was decreased with the increase of temperature because of the reduction of some heat-sensitive components presents in the powder. Similar types of results were noticed by other researchers for foam mat dried tomato powder (Kadam et al., 2012), and alphonso mango powder (Rajkumer et al., 2007).

Table 1. Effect of drying air temperature, foaming agent, foam stabilizer on total soluble solids of tomato powder

\begin{tabular}{lccc}
\hline Concentrations & $60^{\circ} \mathrm{C}$ & $65^{\circ} \mathrm{C}$ & $70^{\circ} \mathrm{C}$ \\
\hline $3 \%$ Egg white $+1 \%$ & $4.0 \pm 0.02^{\mathrm{ab}}$ & $3.95 \pm 0.02^{\mathrm{abc}}$ & $3.88 \pm 0.03^{\mathrm{b}}$ \\
CMC & & & \\
$5 \%$ Egg white $+1 \%$ & $4.06 \pm 0.04^{\mathrm{c}}$ & $3.98 \pm 0.03^{\mathrm{bc}}$ & $3.90 \pm 0.04^{\mathrm{b}}$ \\
CMC & & & \\
$7 \%$ Egg white $+1 \%$ & $4.10 \pm 0.03^{\mathrm{c}}$ & $4.0 \pm 0.05^{\mathrm{c}}$ & $3.93 \pm 0.04^{\mathrm{b}}$ \\
CMC & & & \\
$3 \%$ Egg white $+0.5 \%$ & $3.98 \pm 0.03^{\mathrm{a}}$ & $3.89 \pm 0.04^{\mathrm{a}}$ & $3.84 \pm 0.04^{\mathrm{a}}$ \\
CMC & & & \\
$5 \%$ Egg white $+0.5 \%$ & $4.0 \pm 0.05^{\mathrm{bc}}$ & $3.92 \pm 0.03^{\mathrm{ab}}$ & $3.88 \pm 0.03^{\mathrm{b}}$ \\
CMC & & & \\
$7 \%$ Egg white $+0.5 \%$ & $4.05 \pm 0.03^{\mathrm{bc}}$ & $3.94 \pm 0.04^{\mathrm{ab}}$ & $3.90 \pm 0.04^{\mathrm{b}}$ \\
CMC & & &
\end{tabular}

Values are expressed as mean \pm standard deviation (SD) of 3 replicates $(n=3)$. Values with different superscripts in the same column differ significantly at $\mathrm{p}<0.05$.

\subsection{Ascorbic acid}

Ascorbic acid (vitamin C) is a heat-sensitive watersoluble vitamin. As food processing largely depends on heat processing so the determination of ascorbic acid in processed food is a must for those who are rich in vitamin $\mathrm{C}$ in fresh condition. The results of this study showed that ascorbic acid degradation was largely influenced by drying temperature. The ascorbic acid content of fresh tomato juice was $13.524 \mathrm{mg} / 100 \mathrm{~mL}$ and in reconstituted foam mat dried tomato powder it was within the range $2.35 \pm 0.02$ to $3.00 \pm 0.03 \mathrm{mg} / 100 \mathrm{~mL}$. The result showed that with the rise of temperature the ascorbic acid content decreased in Table 2. This indicated heat-sensitive ascorbic acid destroyed with the rise of temperature. Demiray et al. (2013) found that hot air drying of tomato reduces the ascorbic acid content significantly at high temperature. Similar types of results were also found by other researchers for passion fruit aril (Khamjae and Rojanakorn, 2018), pulses (Mehta et al., 2007), muskmelon (Fernandez et al., 2007), foam mat dried mango powder (Kadam et al., 2010), and onion (Kadam et al., 2009) following heat treatment.

Table 2. Effect of drying air temperatures, foaming agent, foam stabilizer on ascorbic acid $(\mathrm{mg} / 100 \mathrm{~mL})$ of tomato powder

\begin{tabular}{lccc}
\hline Concentrations & $60^{\circ} \mathrm{C}$ & $65^{\circ} \mathrm{C}$ & $70^{\circ} \mathrm{C}$ \\
\hline $3 \%$ Egg white $+1 \%$ & $3.00 \pm 0.03^{\mathrm{c}}$ & $2.84 \pm 0.04^{\mathrm{d}}$ & $2.63 \pm 0.05^{\mathrm{d}}$ \\
CMC & & & \\
$5 \%$ Egg white $+1 \%$ & $2.86 \pm 0.03^{\mathrm{b}}$ & $2.70 \pm 0.02^{\mathrm{b}}$ & $2.51 \pm 0.03^{\mathrm{c}}$ \\
CMC & & & \\
$7 \%$ Egg white $+1 \%$ & $2.73 \pm 0.03^{\mathrm{a}}$ & $2.66 \pm 0.02^{\mathrm{b}}$ & $2.44 \pm 0.03^{\mathrm{b}}$ \\
CMC & & & \\
$3 \%$ Egg white $+0.5 \%$ & $2.96 \pm 0.03^{\mathrm{c}}$ & $2.76 \pm 0.02^{\mathrm{c}}$ & $2.59 \pm 0.05^{\mathrm{d}}$ \\
CMC & & & \\
$5 \%$ Egg white $+0.5 \%$ & $2.81 \pm 0.03^{\mathrm{b}}$ & $2.65 \pm 0.05^{\mathrm{b}}$ & $2.59 \pm 0.03^{\mathrm{d}}$ \\
CMC & & & \\
$7 \%$ Egg white $+0.5 \%$ & $2.70 \pm 0.03^{\mathrm{a}}$ & $2.58 \pm 0.03^{\mathrm{a}}$ & $2.35 \pm 0.02^{\mathrm{a}}$ \\
CMC & & &
\end{tabular}

Values are expressed as mean \pm standard deviation (SD) of 3 replicates $(n=3)$. Values with different superscripts in the same column differ significantly at $\mathrm{p}<0.05$.

\section{$3.3 \mathrm{pH}$ determination}

The $\mathrm{pH}$ of a product usually inversely related to drying temperature. The $\mathrm{pH}$ of fresh tomato juice was found to be 4.59 and in reconstituted foam mat dried tomato powder $\mathrm{pH}$ ranges from $4.47 \pm 0.04$ to $4.71 \pm 0.04$. Both at very high, as well as very low concentration of foaming agent and foam stabilizer concentrations the $\mathrm{pH}$, were significant at $95 \%$ confidence level. From Table 3, it is found that $\mathrm{pH}$ rose with the raise of foaming agent and foam stabilizer concentrations because of the alkaline behavior of egg albumin which is used as the foaming agent. The $\mathrm{pH}$ value in egg albumen is high (almost 9 in the alkali range) which raised the $\mathrm{pH}$ of the reconstituted tomato powder with the addition of albumen (Kadam et al., 2012). A rise in temperature raised molecular vibrations and a reducing aptitude of forming hydrogen bonds raises $\left[\mathrm{H}^{+}\right]$which reduces the $\mathrm{pH}$ in the reconstituted powder.

\subsection{Titratable acidity}

Titratable acidity of fresh tomato juice was $0.346 \%$ and in reconstituted foam mat dried tomato powder ranged from $0.37 \pm 0.01$ to $0.39 \pm 0.03 \%$ (Table 4). It is found that with the raise of foaming agent concentration and temperature, titratable acidity was decreased in reconstituted powder. Statistically, the highest foaming 
Table 3. Effect of drying air temperatures, foaming agent, foam stabilizer on $\mathrm{pH}$ of tomato powder

\begin{tabular}{lccc}
\hline Concentrations & $60^{\circ} \mathrm{C}$ & $65^{\circ} \mathrm{C}$ & $70^{\circ} \mathrm{C}$ \\
\hline $3 \%$ Egg white $+1 \%$ & $4.62 \pm 0.02^{\mathrm{ab}}$ & $4.51 \pm 0.02^{\mathrm{a}}$ & $4.49 \pm 0.02^{\mathrm{ab}}$ \\
CMC & & & \\
$5 \%$ Egg white $+1 \%$ & $4.65 \pm 0.03^{\mathrm{bc}}$ & $4.59 \pm 0.04^{\mathrm{bc}}$ & $4.53 \pm 0.06^{\mathrm{ab}}$ \\
CMC & & & \\
$7 \%$ Egg white $+1 \%$ & $4.71 \pm 0.04^{\mathrm{d}}$ & $4.66 \pm 0.04^{\mathrm{c}}$ & $4.61 \pm 0.02^{\mathrm{c}}$ \\
CMC & & & \\
$3 \%$ Egg white $+0.5 \%$ & $4.57 \pm 0.03^{\mathrm{a}}$ & $4.52 \pm 0.04^{\mathrm{a}}$ & $4.47 \pm 0.04^{\mathrm{a}}$ \\
CMC & & & \\
$5 \%$ Egg white $+0.5 \%$ & $4.63 \pm 0.02^{\mathrm{ab}}$ & $4.57 \pm 0.03^{\mathrm{b}}$ & $4.51 \pm 0.03^{\mathrm{ab}}$ \\
CMC & & & \\
$7 \%$ Egg white $+0.5 \%$ & $4.68 \pm 0.04^{\mathrm{cd}}$ & $4.60 \pm 0.03^{\mathrm{bc}}$ & $4.56 \pm 0.03^{\mathrm{bc}}$ \\
CMC & & & \\
\hline
\end{tabular}

Values are expressed as mean \pm standard deviation (SD) of 3 replicates $(n=3)$. Values with different superscripts in the same column differ significantly at $\mathrm{p}<0.05$.

agent and foam stabilizer concentration, as well as a lowest foaming agent and foam stabilizer concentration, were significant $(\mathrm{p}<0.05)$ at all temperature ranges. As low acidic egg albumin was used as a foaming agent it reduces the acidity of formed powder. The higher drying temperature raised the molecular vibrations which reduce the formation of hydrogen bonds hence increases the acidity of tomato powder. However, the changes in $\mathrm{CMC}$ concentration didn't substantially affect the acidity of foam mat tomato powder.

\subsection{Beta-carotene content}

The $\beta$-Carotene is important provitamin $\mathrm{A}$ which is water-soluble and heat-sensitive. The $\beta$-Carotene content of fresh tomato juice was $3.13 \mathrm{mg}$ and in reconstituted foam mat dried tomato powder it ranges from $1.89 \pm 0.02$ to $2.31 \pm 0.02 \mathrm{mg}$ (Table 5). The high processing temperatures significantly degrade $\beta$-Carotene in tomato

Table 5. Effect of drying air temperatures, foaming agent, foam on $\beta$-Carotene content of tomato powder

\begin{tabular}{lccc}
\hline Concentrations & $60^{\circ} \mathrm{C}$ & $65^{\circ} \mathrm{C}$ & $70^{\circ} \mathrm{C}$ \\
\hline $3 \%$ Egg white $+1 \%$ & $2.09 \pm 0.03^{\mathrm{b}}$ & $1.94 \pm 0.03^{\mathrm{b}}$ & $1.89 \pm 0.03^{\mathrm{a}}$ \\
CMC & & & \\
$5 \%$ Egg white $+1 \%$ & $2.10 \pm 0.03^{\mathrm{a}}$ & $2.02 \pm 0.02^{\mathrm{a}}$ & $1.93 \pm 0.02^{\mathrm{a}}$ \\
CMC & & \\
$7 \%$ Egg white $+1 \%$ & $2.27 \pm 0.03^{\mathrm{de}}$ & $2.14 \pm 0.03^{\mathrm{c}}$ & $2.10 \pm 0.04^{\mathrm{c}}$ \\
CMC & & & \\
$3 \%$ Egg white $+0.5 \%$ & $2.16 \pm 0.03^{\mathrm{c}}$ & $2.11 \pm 0.03^{\mathrm{c}}$ & $2.04 \pm 0.03^{\mathrm{b}}$ \\
CMC & & & \\
$5 \%$ Egg white $+0.5 \%$ & $2.23 \pm 0.03^{\mathrm{d}}$ & $2.15 \pm 0.02^{\mathrm{c}}$ & $2.10 \pm 0.04^{\mathrm{c}}$ \\
CMC & & & \\
$7 \%$ Egg white $+0.5 \%$ & $2.31 \pm 0.02^{\mathrm{e}}$ & $2.26 \pm 0.02^{\mathrm{d}}$ & $2.19 \pm 0.03^{\mathrm{d}}$ \\
CMC & &
\end{tabular}

Values are expressed as mean \pm standard deviation (SD) of 3 replicates $(n=3)$. Values with different superscripts in the same column differ significantly at $\mathrm{p}<0.05$.
Table 4. Effect of drying air temperatures, foaming agent, foam stabilizer on titratable acidity of tomato powder

\begin{tabular}{lccc}
\hline Concentrations & $60^{\circ} \mathrm{C}$ & $65^{\circ} \mathrm{C}$ & $70^{\circ} \mathrm{C}$ \\
\hline $\begin{array}{l}\text { 3\% Egg white }+1 \% \\
\text { CMC }\end{array}$ & $0.37 \pm 0.01^{\mathrm{cd}}$ & $0.38 \pm 0.02^{\mathrm{bc}}$ & $0.39 \pm 0.04^{\mathrm{b}}$ \\
$\begin{array}{l}5 \% \text { Egg white }+1 \% \\
\text { CMC }\end{array}$ & $0.37 \pm 0.03^{\mathrm{ab}}$ & $0.38 \pm 0.03^{\mathrm{ab}}$ & $0.38 \pm 0.01^{\mathrm{ab}}$ \\
$7 \%$ Egg white $+1 \%$ & $0.37 \pm 0.02^{\mathrm{a}}$ & $0.37 \pm 0.02^{\mathrm{a}}$ & $0.38 \pm 0.04^{\mathrm{a}}$ \\
CMC & & & \\
$3 \%$ Egg white $+0.5 \%$ & $0.38 \pm 0.03^{\mathrm{d}}$ & $0.39 \pm 0.03^{\mathrm{c}}$ & $0.39 \pm 0.01^{\mathrm{b}}$ \\
CMC & & & \\
$5 \%$ Egg white $+0.5 \%$ & $0.37 \pm 0.02^{\mathrm{bc}}$ & $0.38 \pm 0.01^{\mathrm{ab}}$ & $0.39 \pm 0.02^{\mathrm{ab}}$ \\
CMC & & & \\
$7 \%$ Egg white $+0.5 \%$ & $0.37 \pm 0.03^{\mathrm{ab}}$ & $0.38 \pm 0.03^{\mathrm{a}}$ & $0.38 \pm 0.02^{\mathrm{ab}}$ \\
CMC & & & \\
\hline
\end{tabular}

Values are expressed as mean \pm standard deviation (SD) of 3 replicates $(n=3)$. Values with different superscripts in the same column differ significantly at $\mathrm{p}<0.05$.

powder. The foaming agent and foam stabilizer concentration exhibited statistically significant difference at different concentration among all temperature range. The $\beta$-Carotene content decreased due to its heatsensitive nature and increased with increasing protein concentration. The findings of the present study are in good harmony with Muratore et al. (2008) and Auisakchaiyoung and Rojanakorn (2015) who informed that degradation of $\beta$-carotene was attributable to drying temperature in cherry tomato and dried Gac aril, respectively. Rajkumar et al. (2006) also found similar results for foam mat dried mango pulp and reported that it may be due to increase in the surface area caused by increasing in foaming agent concentration and thus all particles are dried at low temperature.

\subsection{DPPH free radical scavenging activity}

The DPPH free radicals scavenging activity of fresh

Table 6. Effect of drying air temperatures, foaming agent, foam stabilizer on DPPH free radical scavenging activity of tomato powder

\begin{tabular}{lccc}
\hline Concentrations & $60^{\circ} \mathrm{C}$ & $65^{\circ} \mathrm{C}$ & $70^{\circ} \mathrm{C}$ \\
\hline $3 \%$ Egg white $+1 \%$ & $57.42 \pm 1.75^{\mathrm{bc}} 62.54 \pm 2.82^{\mathrm{bc}} 63.47 \pm 3.42^{\mathrm{bc}}$ \\
CMC & & & \\
$5 \%$ Egg white $+1 \%$ & & $63.88 \pm 3.19^{\mathrm{bc}}$ & $68.67 \pm 2.67^{\mathrm{cd}}$ \\
CMC & $62.07 \pm 2.74^{\mathrm{cd}}$ & & \\
$7 \%$ Egg white $+1 \%$ & $64.09 \pm 3.31^{\mathrm{c}}$ & $67.59 \pm 2.26^{\mathrm{c}}$ & $71.42 \pm 2.46^{\mathrm{d}}$ \\
CMC & & & \\
$3 \%$ Egg white $+0.5 \%$ & $51.60 \pm 2.63^{\mathrm{a}}$ & $52.22 \pm 3.81^{\mathrm{a}}$ & $56.07 \pm 2.9^{\mathrm{a}}$ \\
CMC & & & \\
$5 \%$ Egg white $+0.5 \%$ & $56.48 \pm 0.03^{\mathrm{b}}$ & $60.46 \pm 4.32^{\mathrm{b}} 58.71 \pm 2.37^{\mathrm{ab}}$ \\
CMC & & & \\
$7 \%$ Egg white $+0.5 \%$ & $2.10 \pm 2.30^{\mathrm{cd}}$ & $66.09 \pm 1.94^{\mathrm{bc}} 67.19 \pm 3.56^{\mathrm{cd}}$ \\
CMC & & & \\
\hline
\end{tabular}

Values are expressed as mean \pm standard deviation (SD) of 3 replicates $(n=3)$. Values with different superscripts in the same column differ significantly at $\mathrm{p}<0.05$. 
tomato juice was $84.136 \%$ and in reconstituted foam mat dried tomato powder it ranged from $51.6 \pm 2.63$ to $71.42 \pm 2.46 \%$. The result showed that the increasing foaming agent and foam stabilizers concentrations antioxidant activities in reconstituted samples were increased significantly (Table 6). Depending on processing conditions and product composition, they involve in various chemical pathways and form various compounds which imposed the complexion of nonenzymatic browning reactions. Also, at different temperatures, various compounds having different antioxidant activity are formed at different stages of Maillard reactions. These results also support the findings by other researchers (Giovanelli and Lavelli, 2002; Turkmen et al., 2006; Auisakchaiyoung and Rojanakorn, 2015).

\section{Conclusion}

The results of this study suggest that the use of egg white and carboxymethyl cellulose (CMC) as a foaming agent and foam stabilizer, respectively positively influence the properties of tomato powder. The relatively higher temperature has a negative impact on the quality of the prepared powder. Based on the maximum retention of physical and biochemical properties, the optimum combination of foaming agent, foam stabilizer and the temperature was found to be $7 \%$ egg white $+1 \%$ $\mathrm{CMC}$ at $60^{\circ} \mathrm{C}$ temperature. Based on this study, we can conclude that foam mat dried tomato powder could be an excellent alternative to tomato preservation. A microbial study can be done to observe the nutritional properties changes over time.

\section{Acknowledgments}

Authors thanks to the SUST Research Centre, Shahjalal University of Science and Technology, Bangladesh for their funding to carry out the research works.

\section{References}

Abushita, A.A., Hebshi, E.A., Daood, H.G. and Biacs, P.A. (1997). Determination of antioxidant vitamins in tomatoes. Food Chemistry, 60(2), 207-212. https://doi.org/10.1016/S0308-8146(96)00321-4

Affandi, N., Zzaman, W., Yang, T.A. and Easa, A.M. (2017). Production of Nigella sativa Beverage Powder under Foam Mat Drying Using Egg Albumen as a Foaming Agent. Beverages, 3, 9. https://doi.org/10.3390/beverages3010009

Auisakchaiyoung, T. and Rojanakorn, T. (2015). Effect of foam-mat drying conditions on quality of dried Gac fruit (Momordica cochinchinensis) aril.
International Food Research Journal, 22(5), 20252031.

Bangladesh Bureau of Statistics (BBS). (2017). Yearbook of Agricultural Statistics of Bangladesh. Dhaka, Bangladesh: Planning Division, Ministry of Planning, Government of the People's Republic of Bangladesh.

Biswas, A.K., Sahoo, J. and Chatli, M.K. (2011). A simple UV-Vis spectrophotometric method for determination of $\beta$-carotene content in raw carrot, sweet potato and supplemented chicken meat nuggets. LWT-Food Science and Technology, 44(8), 1809-1813. https://doi.org/10.1016/j.lwt.2011.03.017

Clinton, S.K. (1998). Lycopene: Chemistry, Biology, and Implications for Human Health and Disease. Nutrition Reviews, 56(2), 35-51. https:// doi.org/10.1111/j.1753-4887.1998.tb01691.x

Demiray, E., Tulek, Y. and Yilmaz, Y. (2013). Degradation kinetics of lycopene, $\beta$-carotene and ascorbic acid in tomatoes during hot air drying. $L W T$ -Food Science and Technology, 50(1), 172-176. https://doi.org/10.1016/j.lwt.2012.06.001

Doymaz, I. (2007). Air-drying characteristics of tomatoes. Journal of Food Engineering, 78(4), 12911297. https://doi.org/10.1016/j.jfoodeng.2005.12.047

Febrianto, A., Kumalaningsih, S. and Aswari, A.W. (2012). Process engineering of drying milk powder with foam mat drying method: a study of the effect of the concentration and types of filler. Journal of Basic and Applied Scientific Research, 2(4), 35883592.

Fernandez, R.M., Norena, C.P., Silveira, S.T. and Brandelli, A. (2007). Osmotic dehydration of muskmelon (Cucumis melo): influence of blanching and syrup concentration. Journal of Food Processing and Preservation, 31(4), 392-405. https:// doi.org/10.1111/j.1745-4549.2007.00136.x

Giovanelli, G. and Lavelli, V. (2002). Evaluation of heat and oxidative damage during storage of processed tomato products. Study of heat damage indices. Journal of the Science of Food and Agriculture, 82(11), 1263-1267. https:// doi.org/10.1002/jsfa.1179

Hsu, C.L., Chen, W., Weng, Y.M. and Tseng, C.Y. (2003). Chemical composition, physical properties, and antioxidant activities of yam flours as affected by different drying methods. Food Chemistry, 83(1), 85-92. https://doi.org/10.1016/S0308-8146(03)00053 $-0$

Kadam, D.M., Samuel, D.V., Chandra, P. and Sikarwar, H.S. (2008). Impact of processing treatments and packaging material on some properties of stored dehydrated cauliflower. International Journal of 
Food Science and Technology, 43(1), 1-14. https:// doi.org/10.1111/j.1365-2621.2006.01372.x

Kadam, D.M., Wilson, R.A., Kaur, S. and Manisha. (2012). Influence of foam mat drying on quality of tomato powder. International Journal of Food Properties, 15(1), 211-220. https:// doi.org/10.1080/10942911003763701

Kadam, D.M., Nangare, D.M. and Oberoi, H.S. (2009). Influence of pretreatment on microbial load of stored dehydrated onion slices. International Journal of Food Science and Technology, 44(10), 1902-1908. https://doi.org/10.1111/j.1365-2621.2009.01980.x

Kadam, D.M., Wilson, R.A. and Kaur, S. (2010). Determination of biochemical properties of foammat dried mango powder. International Journal of Food Science and Technology, 45(8), 1626-1632. https://doi.org/10.1111/j.1365-2621.2010.02308.x

Kadam, D.M. and Balasubramanian, S. (2011). Foam mat drying of tomato juice. Journal of Food Processing and Preservations, 35(4), 488-495. https://doi.org/10.1111/j.1745-4549.2010.00492.x

Kalantzakis, G., Blekas, G., Pegklidou, K. and Boskou, D. (2006). Stability and radical-scavenging activity of heated olive oil and other vegetable oils. European Journal of Lipid Science and Technology, 108(4), 329-335. https:// doi.org/10.1002/ejlt.200500314

Kandasamy, P., Varadharaju, N., Kalemullah, S. and Moitra, R. (2012). Preparation of papaya powder under foam-mat drying technique using egg albumin as foaming agent. International journal of Bioresource and Stress Management, 3(3), 324-331.

Khamjae, T. and Rojanakorn, T. (2018). Foam-mat drying of passion fruit aril. International Food Research Journal, 25(1), 204-212.

Moazzem, M.S., Sikder, M.B.H. and Zzaman, W. (2019). Shelf-Life Extension of Wood Apple Beverages Maintaining Consumption-Safe Parameters and Sensory Qualities. Beverages, 5, 25. https://doi.org/10.3390/beverages5010025

Mehta, M.B., Mehta, B., Bapodra, A.H. and Joshi, H.D. (2007). Effect of germination and heat processing on protein, riboflavin, vit-C and niacin content in peas, cowpea, red gram and wheat. Asian Journal of Home Science, 2, 34-38.

Muratore, G., Rizzo, V., Licciardello, F. and Maccarone, E. (2008). Partial dehydration of cherry tomato at different temperature, and nutritional quality of the products. Food Chemistry, 111(4), 887-891. https:// doi.org/10.1016/j.foodchem.2008.05.001

Nindo, C.I. and Tang, J. (2007). Refractance window dehydration technology: a novel contact drying method. Drying Technology, 25(1), 37-48. https:// doi.org/10.1080/07373930601152673

Rajkumar, P. and Kailappan, R. (2006). Optimizing the process parameters for foam mat drying of totapuri mango pulp. Madras Agricultural Journal, 93, 8698.

Ratti, C. (2001). Hot air and freeze-drying of high-value foods: a review. Journal of Food Engineering, 49(4), 311-319. https://doi.org/10.1016/S0260-8774(00) 00228-4

Ratti, C. and Kudra, T. (2006). Drying of foamed biological materials: opportunities and challenges. Drying Technology, 24(9), 1101-1108. https:// doi.org/10.1080/07373930600778213

Shan, O.E., Zzaman, W. and Yang. T.A. (2016). Impact of Different Temperature-Time Profiles during Superheated Steam Roasting on Some Physical Changes of Robusta Coffee. Pertanika Journal of Tropical Agricultural Science, 39(3), 311 - 320.

Turkmen, N., Sari, F., Poyrazoglu, E.S. and Velioglu, Y.S. (2006). Effects of prolonged heating on antioxidant activity and colour of honey. Food Chemistry, 95(4), 653-657. https://doi.org/10.1016/ j.foodchem.2005.02.004

Varastegani, B., Zzaman, W., Harivaindaran, K.V., Yang, T.A., Abdullah, W.N.W., Lee, L.K. and Easa, A.M. (2017) Effect of carrier agents on chemical properties and sensory evaluation of spraydried Nigella sativa. CyTA - Journal of Food, 15 (3), 448-456. https:// doi.org/10.1080/19476337.2017.1297960

Wilson, R.A., Kadam, D.M., Chadha, S. and Sharma, M. (2012). Foam mat drying characteristics of mango pulp. International Journal of Food Science and Nutrition Engineering, 2(4), 63-69. https:// doi.org/10.5923/j.food.20120204.03

Zhang, M., Tang, J. and Mujumdar, A.S. (2006). Trends in microwave related drying of fruits and vegetables. Trends in Food Science and Technology, 17(10), 524-534. https://doi.org/10.1016/ j.tifs.2006.04.011

Zzaman, W., Biswas, R. and Hossain, M.A. (2021). Application of immersion pre-treatment and drying temperatures to improve the comprehensive quality of pineapple (Ananas comosus) slices. Heliyon, 7(1), $\mathrm{e} 05882$.

https://doi.org/10.1016/

j.heliyon.2020.e05882

Zzaman, W., Silvia, D., Abdullah, W.N.W. and Yang, T.A. (2014). Physicochemical and Quality Characteristics of Cold and Hot Press of Nigella sativa L Seed Oil Using Screw Press. Journal of Applied Sciences Research, 10(12), 36-45. 